\title{
Distribution of heavy metals in surface sediments from the South China Sea ecosystem, Malaysia
}

\begin{abstract}
The concentrations of arsenic, cadmium, chromium, copper, mercury, nickel, lead and zinc in surface sediments collected from the east coast of peninsular Malaysia, along the South China Sea, were measured by two methods instrumental neutron activation analysis and inductively coupled plasma mass spectroscopy. The obtained results were use to determine the areal distribution of the metals of in the east coast of peninsular Malaysia and potential sources of these metals to this environment. The geochemical data propose that most of the metals found in the east coast of peninsular Malaysia constitute a redistribution of territorial materials within the ecosystem. Then, the metal concentrations can be considered to be present at natural background levels in surface sediments.
\end{abstract}

Keyword: Heavy metal; Malaysia; Marine ecosystem; Surface sediments 